\title{
«МЯГКАЯ СИЛА» БРАЗИЛИИ В ЕВРОСОЮЗЕ В ПЕРИОД НАХОЖДЕНИЯ У ВЛАСТИ ЛУЛЫ ДА СИЛВЫ.
}

\begin{abstract}
Аннотация. Сегодня Бразилия для обеспечения лидерских позиций в политике и экономике применяет новые информационно-коммуникационные технологии, направленные на распространение бразильских иенностей в мире и в частности в ЕС. Одним из направлений внешней политики Лулы да Силвы было расширение взаимоотношений со странами ЕС, которые бы стали серьезным конкурентом США в Бразилии и в силу развития партнерских стратегических связей, могли оказать информационную поддержку Бразилии в результате инбормационного и экономического давления со стороны США. Методологическая база исследования основана на системном, структурно-функииональном, сравнительно-политическом и культурно-иивилизационном подходах, методах индукиии, дедукиии, анализа, синтеза, моделирования, экспертных оценок, наблюдения. Разработка информационно оснащенных правительственных и посольских сайтов Федеративной Республики Бразилии, рассчитанных на работу с зарубежной аудиторией стран и регионов Европейского Союза, способствовала развитию двухсторонних контактов между двумя регионами начиная от экономических и политических проектов и заканчивая научно - культурным сотрудничеством.
\end{abstract}

Ключевые слова: политика, управление, Бразилия, ЕС, США, мягкая сила, межкультурная коммуникация, политическая коммуникация, репутация, имидж

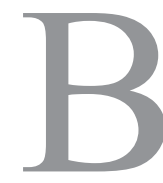

начале XXI века в ряде стран Латинской Америки и в частности в Бразилии началось применение новых информационно-коммуникационных технологий, которые стали эффективным средством выстраивания внешнеполитических отношений со многими со странами ЕС.

Говоря о внешней политики Бразилии в целом необходимо отметить, что, прежде всего, она направлена на формирование независимой политики в мире и самостоятельности от США.

С победой на выборах Лулы да Силвы в январе 2003 года начинается новый этап в истории двухстороннего сотрудничества между ЕС и Бразилией.

Бразилия стремится выдвинуть на первый план региональную интеграцию как важную особенность развития стратегии страны, а также международное стратегическое партнерство, тем самым добивается качественно нового статуса на политической арене.

Участие в 2003 году в ВТО и в составе Большой 20-ки (G- 20) выражают готовность страны играть активную роль в многосторонних отношениях и представляют себя как вероятного глобального игрока. Одним из главных приоритетов внешней политики с 2003 года является борьба Бразилии за получение места постоянного члена в Совете Безопасности $\mathrm{OOH}$, представляя интересы от Латинской Америки и развивающихся стран. США против постоянного членства Бразилии в Совете Безопасности, т.к. она является региональным лидером и возглавляет движение против гегемонии США в Латинской Америке. Вхождение Бразилии в качестве постоянного члена в Совет Безопасности ООН усилит ее позицию в регионе, в чем не заинтересованы США. В связи с этим для успешной реализации внешнеполитических целей Бразилии необходимо создание и управление коммуникационной среды для поддержки страны на международном уровне, что закрепит за ней легитимность нового статуса.

Европейский союз как один из участников международного процесса стремится к независимой внутренней и внешней политике от США, как и Бразилия, стремится иметь меньше экономических завязок с США. Обратившись к официально опубликованному на сайте МИДа Бразилии документу Balanço de Política Externa 2003/20101 можно сделать вывод, что правительство Бразилии попыталось расширить и укрепить отношения со странами, взгляды которых относительно существующего международного положения расценены были как сходящиеся. Стремление к построению

\footnotetext{
${ }^{1}$ Balanço de Política Externa 2003/2010. [Электронный реcypc]. URL: http://www.itamaraty.gov.br/temas/balanco-depolitica-externa-2003-2010 (29.04.2011).
} 


\section{Мировой порядок}

многополярного мира объединяет эти страны, цель которого противостояние гегемонии США.

ЕС заинтересован в придании нового импульса отношениям с МЕРКОСУР для устранения тарифных барьеров для торговли и иностранных инвестиций, через стратегическое партнерство с Бразилией.

На основе официальных документов можно сделать вывод, что использование «мягкой силы» ${ }^{2}$ Бразилии направлено на:

1) распространение Бразилией идей интеграции на всем латиноамериканском континенте и за ее пределами;

2) повышение статуса и престижа Бразилии;

3) противостояние глобализации в ее ассиметричных вариантах.

Целевой аудиторией первой и третьей функций являются страны Латинской Америки и развивающиеся страны, второй - мировое общественное мнение, однако данные идеи в конечном итоге направлены на соблюдение бразильских интересов.

В Стратегическом документе 2001-2006 и Национальной программе 2002-2006 гг. ${ }^{3}$ четко обозначены правительством цели сотрудничества с Европейским союзом: 1) экономические реформы, 2) социальное развитие и коллективная ответственность за ее реализацию, 3) охрана окружающей среды.

Первый бизнес саммит ЕС и Бразилия состоялся 4 июля 2007 года параллельно с первой встречей политиков на высшем уровне. Данное мероприятие прошло под патронажем Европейской комиссии, председательства Португалии в ЕС и правительством Бразилии. По результатам круглого стола компании сделали следующие рекомендации для политических лидеров, с целью обогащения стратегического партнерства:

- «Стратегическое партнерство ЕС - Бразилия: это партнерство рассматривается как платформа для диалога»

\footnotetext{
${ }^{2}$ Мягкая сила - форма политической власти, способность добиваться желаемых результатов на основе добровольного участия, симпатии и привлекательности, в отличие от «жесткой силы», которая подразумевает принуждение. По словам введшего этот термин американского политолога Джозефа Ная, язык и культура страны - это «мягкая сила», которая играет ключевую роль в международных отношениях, влияя напрямую, или косвенно, на мировую политику и деловые связи.

${ }^{3}$ Country strategy paper 2001- 2006 and national indicative programme 2002-2006. [Электронный ресурс]. URL:http:// www.eeas.europa.eu/brazil/csp/02_06_en.pdf (10.03.2013).
}

- «Инвестиции, инфраструктура и государственно-частное партнерство: компании полностью поддерживают политику, направленную на увеличение государственных инвестиций в инфраструктуру. Участие частного сектора в рамках государственно-частного партнерства и общественных грантов будет способствовать повышению результативности и эффективности этих инвестиций.

- Конкурентоспособность и инновации: ЕС и Бразилии следует осуществлять политику, повышения конкурентоспособности и инноваций в целях достижения основных целей роста и занятости.

- Энергетика и изменене климата: EC и Бразилия должны работать вместе для заключения многостороннего соглашения, которое будет содержать решение проблемы изменения климата. Существует необходимость установить стандарты на биотопливо и обеспечить открытие рынков для их сырья» ${ }^{4}$.

Данный пример хорошо показывает, как заинтересованные компании, применяя системно принципы, добились необходимого результата.

Кроме того, важной задачей Бразилии в налаживании стратегического сотрудничества с ЕС в последние годы является формирование положительной репутации страны и представителей власти.

Здесь следует отметить, что Бразилия в рамках программы «Бразилия - экспортер» принимала активные меры не только для пропаганды своей культуры, о чем говорилось выше, но и занималась улучшением своего экономического имиджа как у себя в стране, так и за ее пределами. В рамках этой программы совершенствовалась система страхования экспортных кредитов, создавались кредитные линии для мелких экспортеров, повышалась профессиональная подготовка предпринимателей в сфере внешней торговли, расширялись возможности микро и малых предприятий в дизайне выпускаемой продукции 5 .

Важнейшим направлением политической коммуникации Бразилии в ЕС в период нахождения у власти правительства Лулы да Сильвы, являлось также создание благоприятного политического имиджа на

\footnotetext{
${ }^{4}$ THE 1-st EU- BRAZIL (официальный сайт). [Электронный pecypc]. URL:http://www.summits.aip.pt/brasil/PT/EU-Brazil. asp (20.03.2013).

5 Энциклопедия Латинская Америка. // Под ред. В.М.

Давыдова - М: Экономика, 2013. - С.444
} 


\section{Тренды и управление 3(7) • 2014}

мировой арене. Здесь надо отметить, что Бразилия практиковала и продолжает практиковать политику лавирования в своих международных контактах. Так, являясь, самым крупным партнером европейцев в Южной Америке ${ }^{6}$, Бразилия активно развивает свои отношения со странами Азии, Африки и с Россией, вызывая не малые опасения у своих партнеров из ЕС и США, которые в свою очередь пытаются убедить Бразилию в нестабильности ее отношений с вышеперечисленными регионами. ${ }^{7}$

Такая политика нашла свое отражение в европейских СМИ. Имидж и репутация Бразилии в определенной степени эволюционировали в европейских СМИ в период с 2003 - по 2011 гг.

Если до первого саммита Бразилии - ЕС состоявшегося в 2007 году репутация страны и представителей власти была крайне низкой и негативной в европейских $\mathrm{CM}^{8}$, которые зачастую в качестве источников опирались на прессу США, то начиная с 2007 года, репутация и имидж Бразилии значительно улучшился.

В качестве обвинений, которые выдвигались кабинету Лулы да Сильвы можно выделить следующие яркие темы:

- $\quad$ коррупционность правящей элиты;

- $\quad$ сближение с леворадикальными правительствами

Латиноамериканских стран, таких как Венесуэла,

Куба, Никарагуа.

- связь с террористическими организациями

Латинской Америки;

- политическая, социальная и экономическая нестабильность в стране;

- $\quad$ отсутствие демократических норм в стране9.

В немалой степени за улучшение имиджа и репутации Бразилии в этот период отвечали технологии политической коммуникации удачно применяемые

\footnotetext{
${ }^{6}$ По данным Евростата /официальной статистической службы ЕС.

${ }^{7}$ Манойло А.В. Национально-государственные модели психологического управления конфликтами. // ОбозревательObserver. -2008. - №2. - С.118.

${ }^{8}$ В анализе были задействованы следующие издания европейских СМИ: французские периодические издания - Le figaro, Le parisien, Le monde, humanite; немецкие периодические издания - welt, faz, stern; британское периодическое издание guardian; итальянское периодическое издание repubblica; испанские периодические издания - El mundo, El Pais, rebelion.

${ }^{9}$ Приблизительно 85\% всех публикаций по данной проблематике.
}

кабинетом Лулы да Сильвы, такие как репутационный менеджмент, имиджмейкинг, межкультурные коммуникации, общественная дипломатия и др.

В качестве каналов политической коммуникации Бразилии выступали электронные СМИ, информационные агентства Бразилии, сайт МИДа и посольские сайты, которые вещают на зарубежные аудитории EC.

Значительный вклад в построении дипломатического диалога между Бразилией и ЕС, оказало создание Интернет-сайтов независимых информационных агентств $^{10}$, таких как Agencia Brasil ${ }^{11}$, Agencia Estado ${ }^{12}$, которые за период 2006-2011 гг. значительно адаптировались в мировом информационном пространстве и не уступают известным информационным агентствам развитых государств. ${ }^{13}$

Помимо информационных агентств, вещающих на зарубежную аудиторию и играющих важнейшую роль во внешней политики Бразилии, следует выделить электронные СМИ, чья деятельность также связана с использованием коммуникационных технологий в области репутационного менеджмента, направленного на создание положительной репутации стран Бразилии в мире.

\footnotetext{
${ }^{10}$ Информационное агентство «Agencia Brasil» - http:// agenciabrasil.ebc.com.br/, Информационное агентство «Agencia Estado» [Электронный pecypc]. URL: http://www. ae.com.br/ (12.03.2013).

${ }^{11}$ Бразильское информационное агентство новостей (Agencia Brasil). Было создано в 1990 - х гг., активную международную новостную работу проводит с 2003 года. Курируется правительством Бразилии. Пользуется большой популярностию в Португалии и в других странах ЕC.

${ }^{12}$ Государственное агентство Бразилии (Agencia Estado). Одно из первых информационных агентств Бразилии. Было создано в 1970 году для оказания оперативной поддержки СМИ Бразилии, таким как O Estado-де-Сан-Паулу и радио Эльдорадо. На протяжении многих лет создает новости для малых, средних и крупных газет, и радиостанций по всей Бразилии. В 1991 году Государственное агентство приобрело компания «Teleinformática», которая способствовала работе агентства направленной на поддержку национальных и международных финансовых рынков. С приобретением агентства его услуги предоставляют клиентам на рынке информацию и анализ новостей, которые оказывают непосредственное влияние на прибыльность бизнеса.

${ }^{13}$ Виноградова Е.А. Информационно-коммуникационное обеспечение политики стран АЛБА в ЕС в начале XXI века. NB: Международные отношения.№2., 2013 - 0. - №0. - С.00. DOI: 10.7256/2306-4226.0.0.725. 0,8 п.л. http://e-notabene. $\mathrm{ru} /$ wi/article_725.html
} 


\section{Мировой порядок}

Среди ведущих бразильских электронных изданий можно выделить ${ }^{14} \mathrm{O}$ Globo, Folha de Sao Paulo, Valor Economico, A Tarde "Brasil Economico, Correio Brasilience, O Estado de Sao Paulo, Jornal da Brasilia, Jornal de Comercio ISTO EVEJA.

Таким образом, европейские новостные агентства и периодические издания в освещении новостей латиноамериканских стран опираются на информацию СМИ Бразилии, а не на зачастую дискредитирующую информацию со стороны «лживых источников» США. Разработка и корректировка правительственных вебсайтов Бразилии в период президентства Лулы да Сильвы способствовала развитию общественной дипломатии посредством сетевого общения между главой бразильского государства и целевыми аудиториями в мировом масштабе.

В результате с 2008 - 2011 гг. в европейских СМИ доминирующими темами являются:

• Бразилия мировой экономический гигант;
- улучшение экономической, социальной и политической сфер Бразилии;

- Б Бразилия надежный стратегический партнер ЕC, которому нужно избежать тесных контактов с Китаем, Индией, США и с Россией;

- политическая стабильность в стране и развитие демократии ${ }^{15}$.

Таким образом, следует отметить, что информатизация Бразилии в начале XXI века способствовала использованию технологий политической коммуникации, и в частности «мягкой силы», для налаживания внешнеполитических отношений со странами ЕС.

Улучшив качество правительственных и посольских сайтов, информационных агентств, вещающих на зарубежную аудиторию, Бразилии удалось не только поправить отрицательную репутацию, которая была у нее до 2007 года, но и значительно повысить уровень общественной дипломатии посредством сетевого общения с европейской аудиторией.

\section{Библиография}

1. Balanço de Política Externa 2003/2010. [Электронный ресурc]. URL: http://www.itamaraty.gov.br/temas/ balanco-de-politica-externa-2003-2010 (29.04.2011).

2. Country strategy paper 2001-2006 and national indicative programme 2002-2006. [Электронный ресурс]. URL:http://www.eeas.europa.eu/brazil/csp/02_06_en.pdf (10.03.2013).

3. THE 1-st EU-BRAZIL (официальный сайт). [Электронный ресурс]. URL:http://www.summits.aip.pt/ brasil/PT/EU-Brazil.asp (20.03.2013).

4. Энциклопедия Латинская Америка. // Под ред. Давыдова В.М. - М: Экономика, 2013.-С.444

5. Информационное агентство «Agencia Brasil»-http://agenciabrasil.ebc.com.br/

6. Информационное агентство «Agencia Estado» [Электронный pecypc]. URL: http://www.ae.com.br/ (12.03.2013).

\footnotetext{
${ }^{14}$ Газета «O Globo» [Электронный ресурc]. URL: http://oglobo.globo.com/, Газета «Folha de Sao Paulo» [Электронный pecypc]. URL: -http://www.folha.uol.com. br/, Газета «Valor Economico» [Электронный ресурс]. URL: http://www.valoronline.com.br/, Газета «A Tarde» -[Электронный ресурc]. URL: http://www.atarde.com. br/, Газета «Brasil Economico» [Электронный pecypc]. URL: http://www.brasileconomico.com.br/, Газета «Correio Brasilience» [Электронный ресурc]. URL: -http://www. correioweb.com.br/, Газета «O Estado de Sao Paulo» [Электронный ресурc]. URL: http://www.estadao.com.br/, Журнал «Jornal da Brasilia» [Электронный pecypc]. URL: -http://www.jornaldebrasilia.com.br/, Журнал «Jornal de Comercio» [Электронный pecypc]. URL: http://www.jc.uol. com.br/, Журнал «ISTO Е» [Электронный ресурc]. URL: http://www.istoe.com.br/capa, Журнал «VEJA» [Электронный pecypc]. URL: http://veja.abril.com.br/ (12.03.2013).
} ${ }^{15}$ Приблизительно 78\% всех публикаций по данной пробле-
матике. 


\section{Тренды и управление 3(7) • 2014}

7. Виноградова Е.А. Информационно-коммуникационное обеспечение политики стран АЛБА в ЕС в начале XXI века. NB: Международные отношения.№2., 2013 - 0.-№0.-C.0-0. DOI: 10.7256/23064226.0.0.725. 0,8 п.л. http://e-notabene.ru/wi/article_725.html

8. Манойло А.В. Национально-государственные модели психологического управления конфликтами. // Обозреватель-Observer.-2008.-№2.

9. Манойло А.В. «Финиковые революции»: стихия или управляемый хаос?//Международная жизнь. - 2011.-№5. - С. 63-78.

10. Манойло А.В. Роль стратегий управляемого хаоса в формировании нового миропорядка // Право и политика. - 2014. - №5. - С. 638-651. DOI: 10.7256/1811-9018.2014.5.11816.

11. Манойло А.В. Несиловое регулирование международных конфликтов. Культурно-цивилизационные парадигмы. // Космополис.-2008.-№2. - С.168-174.

12. Манойло А.В. Психологические операции: модели и технологии управления конфликтами. // Политэкс (Политическая экспертиза).-2008.-№3.-С. 62-73.

13. Манойло А.В. Психологические операции США в Ираке. // Космополис.-2008.-№1. - С.124-128.

14. Манойло А.В. Модели информационного воздействия на разрешение международных и внутриполитических конфликтов. // Федерализм.-2008.-№3. - С. 159-172.

15. Виноградова Е.А. Информационно-коммуникационное обеспечение политики стран АЛБА в ЕС в начале XXI века // NB: Международные отношения. - 2013. - 1. - С. 1 - 11. DOI: 10.7256/2306-4226.2013.1.725. URL: http://www.e-notabene.ru/wi/article_725.html

16. Бельянинов А.Ю. Выход из интеграционного кризиса через повышение эффективности деятельности СНГ // Политика и Общество. - 2013. - 2. - С. 176 - 182. DOI: 10.7256/1812-8696.2013.02.7.

17. Филимонов Г.Ю. Актуальные вопросы формирования стратегии «мягкой силы» во внешней политике Российской Федерации // Международные отношения. - 2013. - 4. - C. 443 - 451. DOI: 10.7256/2305-560Х.2013.4.9419.

18. Мартынов А.В. Современное право и публичное управление: проблемы методологии и соотношения // NB: Экономика, тренды и управление. - 2013. - 4. - С. 1 - 15. DOI: 10.7256/2306-4595.2013.4.924. URL: http://www.e-notabene.ru/etc/article_924.html

19. Алейников А.В. Системные конфликты в России: концептуальные основания анализа. Статья 1. // NB: Проблемы общества и политики. - 2013. - 7. - C. 94 - 140. DOI: 10.7256/2306-0158.2013.7.2306. URL: http://www.e-notabene.ru/pr/article_2306.html

20. Хизриева С.С. Информационное обеспечение внешней политики Бразилии в Евросоюзе // Международные отношения. - 2013. - 3. - С. 353 - 355. DOI: 10.7256/2305-560X.2013.3.8879.

21. Будаев А.В. Публичная дипломатия в российско-бразильских отношениях // Политика и Общество. - 2014. - 2. - C. 197 - 205. DOI: 10.7256/1812-8696.2014.2.10164.

22. Чихарев И.А., Столетов О.В. Университеты как субъекты публичной дипломатии // Международные отношения. - 2013. - 4. - С. 519 - 529. DOI: 10.7256/2305-560Х.2013.4.9752.

23. Г. Ю. Филимонов, С. А. Цатурян Социальные сети как инновационный механизм «мягкого»воздействия и управления массовым сознанием // Политика и Общество. - 2012. - 1. - С. 65 - 75.

24. Коробейников А.Г., Гришенцев А.Ю., Святкина М.Н. Применение интеллектуальных агентов магнитных измерений для мониторинга объектов железнодорожной инфраструктуры // NB: Кибернетика и программирование. - 2013. - 3. - С. 9 - 20. DOI: 10.7256/2306-4196.2013.3.8737. URL: http://www.enotabene.ru/kp/article_8737.html

\section{References}

1. Balanço de Política Externa 2003/2010. [Elektronnyi resurs]. URL: http://www.itamaraty.gov.br/temas/ balanco-de-politica-externa-2003-2010 (29.04.2011).

2. Country strategy paper 2001-2006 and national indicative programme 2002-2006. [Elektronnyi resurs]. URL:http://www.eeas.europa.eu/brazil/csp/02_06_en.pdf (10.03.2013). 


\section{Мировой порядок}

3. THE 1-st EU-BRAZIL (ofitsial'nyi sait). [Elektronnyi resurs]. URL:http://www.summits.aip.pt/brasil/PT/ EU-Brazil.asp (20.03.2013).

4. Entsiklopediya Latinskaya Amerika. // Pod red. Davydova V.M. - M: Ekonomika, 2013.-S.444

5. Informatsionnoe agentstvo «Agencia Brasil»-http://agenciabrasil.ebc.com.br/

6. Informatsionnoe agentstvo «Agencia Estado» [Elektronnyi resurs]. URL: http://www.ae.com.br/ (12.03.2013).

7. Vinogradova E.A. Informatsionno-kommunikatsionnoe obespechenie politiki stran ALBA v ES v nachale XXI veka. NB: Mezhdunarodnye otnosheniya.№2., 2013 - 0.-№0.-S.0-0. DOI: 10.7256/2306-4226.0.0.725. 0,8 p.l. http://e-notabene.ru/wi/article_725.html

8. Manoilo A.V. Natsional'no-gosudarstvennye modeli psikhologicheskogo upravleniya konfliktami. // Obozrevatel'-Observer.-2008.-№2.

9. Manoilo A.V. «Finikovye revolyutsii»: stikhiya ili upravlyaemyi khaos?//Mezhdunarodnaya zhizn'. - 2011.№5. - S. 63-78.

10. Manoilo A.V. Rol' strategii upravlyaemogo khaosa v formirovanii novogo miroporyadka // Pravo i politika. - 2014. - №5. - S. 638-651. DOI: 10.7256/1811-9018.2014.5.11816.

11. Manoilo A.V. Nesilovoe regulirovanie mezhdunarodnykh konfliktov. Kul'turno-tsivilizatsionnye paradigmy. // Kosmopolis.-2008.-№2. - S.168-174.

12. Manoilo A.V. Psikhologicheskie operatsii: modeli i tekhnologii upravleniya konfliktami. // Politeks (Politicheskaya ekspertiza).-2008.-№3.-S. 62-73.

13. Manoilo A.V. Psikhologicheskie operatsii SShA v Irake. // Kosmopolis.-2008.-№1. - S.124-128.

14. Manoilo A.V. Modeli informatsionnogo vozdeistviya na razreshenie mezhdunarodnykh i vnutripoliticheskikh konfliktov. // Federalizm.-2008.-№3. - S. 159-172.

15. Vinogradova E.A. Informatsionno-kommunikatsionnoe obespechenie politiki stran ALBA v ES v nachale XXI veka // NB: Mezhdunarodnye otnosheniya. - 2013. - 1. - C. 1 - 11. DOI: 10.7256/2306-4226.2013.1.725. URL: http://www.e-notabene.ru/wi/article_725.html

16. A.Yu. Bel'yaninov Vykhod iz integratsionnogo krizisa cherez povyshenie effektivnosti deyatel'nosti SNG // Politika i Obshchestvo. - 2013. - 2. - C. 176 - 182. DOI: 10.7256/1812-8696.2013.02.7.

17. Filimonov G.Yu. Aktual'nye voprosy formirovaniya strategii «myagkoi sily» vo vneshnei politike Rossiiskoi Federatsii // Mezhdunarodnye otnosheniya. - 2013. - 4. - C. 443 - 451. DOI: 10.7256/2305-560X.2013.4.9419.

18. Martynov A.V. Sovremennoe pravo i publichnoe upravlenie: problemy metodologii i sootnosheniya // NB: Ekonomika, trendy i upravlenie. - 2013. - 4. - C. 1 - 15. DOI: 10.7256/2306-4595.2013.4.924. URL: http://www. e-notabene.ru/etc/article_924.html

19. Aleinikov A.V. Sistemnye konflikty v Rossii: kontseptual'nye osnovaniya analiza. Stat'ya 1. // NB: Problemy obshchestva i politiki. - 2013. - 7. - C. 94 - 140. DOI: 10.7256/2306-0158.2013.7.2306. URL: http://www. e-notabene.ru/pr/article_2306.html

20. Khizrieva S.S. Informatsionnoe obespechenie vneshnei politiki Brazilii v Evrosoyuze // Mezhdunarodnye otnosheniya. - 2013. - 3. - C. 353 - 355. DOI: 10.7256/2305-560X.2013.3.8879.

21. Budaev A.V. Publichnaya diplomatiya v rossiisko-brazil'skikh otnosheniyakh // Politika i Obshchestvo. 2014. - 2. - C. 197 - 205. DOI: 10.7256/1812-8696.2014.2.10164.

22. Chikharev I.A., Stoletov O.V. Universitety kak sub"ekty publichnoi diplomatii // Mezhdunarodnye otnosheniya. - 2013. - 4. - C. 519 - 529. DOI: 10.7256/2305-560X.2013.4.9752.

23. G. Yu. Filimonov, S. A. Tsaturyan Sotsial'nye seti kak innovatsionnyi mekhanizm «myagkogo» vozdeistviya i upravleniya massovym soznaniem // Politika i Obshchestvo. - 2012. - 1. - C. 65 - 75.

24. Korobeinikov A.G., Grishentsev A.Yu., Svyatkina M.N. Primenenie intellektual'nykh agentov magnitnykh izmerenii dlya monitoringa ob"ektov zheleznodorozhnoi infrastruktury // NB: Kibernetika i programmirovanie. - 2013. - 3. - C. 9 - 20. DOI: 10.7256/2306-4196.2013.3.8737. URL: http://www.e-notabene. $\mathrm{ru} / \mathrm{kp} /$ article_8737.html 